\title{
Investigation of the Effect of Drill Bit Rotation Speed on Sustainable Drilling
}

\author{
Niyazi Bilim ${ }^{1 *}$, Sertaç Dündar ${ }^{1}$, Bilgehan Kekeç ${ }^{1}$ and Arif Emre Dursun ${ }^{2}$ \\ ${ }^{1}$ Department of Mining Engineering, Selcuk University Konya, TURKEY \\ ${ }^{2}$ Programme of Occupational Health and Safety, Selcuk University, Konya, TURKEY
}

\begin{abstract}
Estimation of rock drillability is vital for mining and boring operations. For this purpose, many researchers have developed various models and equations to estimate rock drillability. Most of these models aim to determine the drillability of rock and the penetration rate by using the physical and mechanical properties of rocks. Although drillability primarily depends on rock properties, other parameters have an impact on drillability as well. One of these parameters is the rotation speed of the bit. This study investigates the effect of rotation speed of the bit on drilling performance. Drilling tests were performed in the laboratory using rotary core drilling and a diamond drilling machine. The relationships between the physical rock properties and the penetration rate were investigated on 15 different rock types and four different rotation speeds were applied to determine the effect of rotation speed of bit on drilling. The uniaxial compressive strength, density, and $\mathrm{P}$ wave velocity show strong correlations with the penetration rate. In addition, if the values of the physical and mechanical properties of the rock increase, the effect of the rotation speed on the penetration rate decreases, i.e., increasing the rotation speed of the bit slightly affects drillability on hard and solid formations.
\end{abstract}

Keywords: drillability, core drilling, rotary drilling, penetration rate, rotation speed

\section{Introduction}

Drilling is one of the most essential operations in the mining industry, beginning from the exploration phase and continuing throughout all stages of production to the end of mine life (Taheri et al. 2016). In addition, drilling is widely using in the construction industry and other engineering operations. Various drillholes (blastholes, injection holes, borehole, diamond wire holes in natural stone mines, etc.), are needed during development and production activities in underground and open-pit mines as well as in dam, tunnel, road construction and sewage systems. For effective drilling operations, it is first necessary to gather information about the formation to be drilled. Drilling should then be performed after selecting appropriate drilling equipment and drilling parameters (thrust, pressure, rotational speed, flushing).

Prediction of the drillability of rocks is vital for planning and performing the drilling process. Although, drilling is affected by several factors, the most important ones are related to the geological and mechanical properties of formation (Protodyakonov 1963, Paone et al 1969, Tandanand and Unger 1975, Pathinkar and Misra 1976, Rabia 1985, Perrin et al 1977). Determining the penetration rate is vital for planning a project and calculating the operation costs. The prediction of drilling affects the selection of drilling equipment, the efficiency of drilling equipment, project costs and the process of drilling operations.

The penetration rate reflects the progression of the drilling bit into the rock during a certain period of time, and is generally expressed as " $\mathrm{m} / \mathrm{min} "$. Drillability and penetration rate can be defined as similar terms. While drillability indicates whether penetration is easy or hard, penetration rate indicates whether it is fast or slow (Bilim 2011).

At the present time, two types of drilling methods are used. These methods are percussive drilling and rotary drilling and designing a drilling system involves selecting one of these drilling methods. Rock drillability should be analyzed separately for each drilling method because of the difference in drilling systems and drillability prediction models need to be developed separately for each drilling method.

Drillability can be determined by means of an improved drillability index and tests. Laboratory and in-situ tests with drilling machines, DRI (drilling rate index), Mohs hardness and brittleness test can be used for determining drillability.

Factors that influence drillability of rocks can be investigated using three main parameter groups, which include drilling equipment properties, rock properties and environmental conditions. Drilling equipment properties and environmental conditions are parameters that can be changed, while rock properties are parameters that can not be varied. Parameters used for the prediction of drillability include the physico-mechanical properties of rock, the chemical properties of rock, and the petrographic properties and mineralogical properties of rock. In addition, rock abrasiveness also affects rock drillability.

Many of the studies already conducted show that the parameters that affect drilling are rock mass parameters, such as Mohs hardness, texture of rock, porosity, density, abrasiveness, $\mathrm{P}$ wave velocity, elastic and plastic properties,

* Corresponding Author: N. Bilim, bilim@ selcuk.edu.tr, phone: +90 332-2232099

Copyright @ 2017 Canamaple Academia Services, http://press.camdemia.ca

DOI: 10.15273 /gree.2017.02.037 
Young modulus, uniaxial compressive strength, point load strength, tensile strength, Shore hardness, Schmidt hardness and RQD (Jimeno et al 1995, Thuro 1997, Kahraman et al 2000, Hoseinie et al 2006, Taheri et al 2016).

The frequency of evaluating these parameters for developing drillability prediction models and investigating drillability is shown in Figure 1. Based on Figure 1 the predominant parameters used in drillability prediction are the uniaxial compressive strength, the tensile strength, Young's modulus, hardness, density and Schmidt hardness.

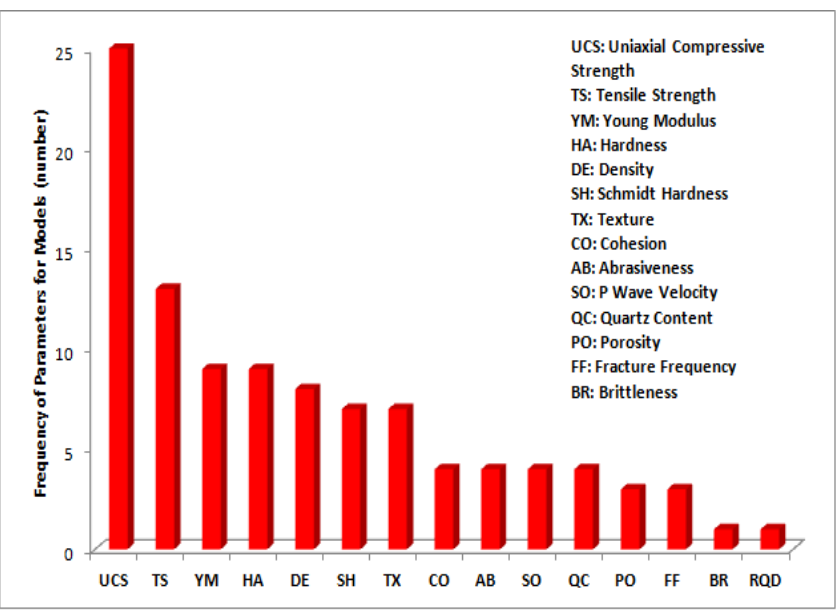

Figure 1. Frequency of parameters used in drillability prediction (Taheri et al. 2016).

Howarth et al (1985), conducted drillability tests on 10 different rock types. Significant relations between penetration rate and uniaxial compressive strength, density, porosity, $\mathrm{P}$ wave velocity and Schmidt hardness were determined. Kahraman et al (2000) investigated relations between the penetration rate and the uniaxial compressive strength, the Brazilian tensile strength, the point load strength and Schmidt hardness. They found good correlation relations.

Soyer (2009) conducted DRI tests on 32 different rock types. Relations between mineralogical-petrographical properties of rocks and strength tests (uniaxial compressive strength and indirect tensile strength), index tests (Schmidt hardness, Shore hardness, axial and diametrical point load strength) was investigated. The research concluded that the hardness of rocks, the strength of rocks and their brittleness are influential on drillability and the petrographical properties are slightly influential on drillability.

Kahraman (1999) developed a multiple regression model for the prediction of penetration rates of rotary blasthole drills using the data obtained from field observations. The results indicated that the parameters that significantly affect the penetration rate of rotary blasthole drills included the weight on the bit, the rotational speed, the bit diameter and the compressive strength. Ekincioğlu (2008) emphasized that there exist good relationships between the physical and mechanical properties of the rock and the DRI index. In this study the point load strength shows the best relation with DRI.

As stated above the uniaxial compressive strength, tensile strength, density, hardness and Schmidt hardness values are generally used on drillability prediction models.
The aim of this study is to investigate the relations between determined parameters and penetration rate. In addition, the study will investigate the effect of drill bit rotation speed on the penetration rate in a core drilling system.

\section{Background}

The drillability of the rock indicates the rate that the drill bit makes progress into the rock. Rock drillability depends on rock hardness, strength, brittleness, discontinuities and rock mass properties. Many parameters affect the drillability of rocks with respect to drilling machines. For example, rotary speed and torque, water, slurry or air pressure and volume (for cleaning the bore hole), pressure force and speed, (pulldown force and speed), bit diameter and type, drill rig type, depth and diameter of hole etc.

An increase in rotation speed will bring about an increase in penetration rate, but within certain limits. In soft formations, where chips are produced by cutting/tearing actions, the increase in penetration rate is nearly proportional to the change in rotation speed (if the chips are all being cleared as soon as they are produced). The sliding of teeth complicates the operation of rollers on hard rocks as the rock breaks unevenly (Figure 2). Failing to completely clear the cuttings can also become a large problem at high speeds. The result is that there is little advantage in increasing the rotary speed above recommended levels. However, bit wear increases rapidly as rotation speed is increased, both for rollers and for hammer bits (ADITCL 1997).

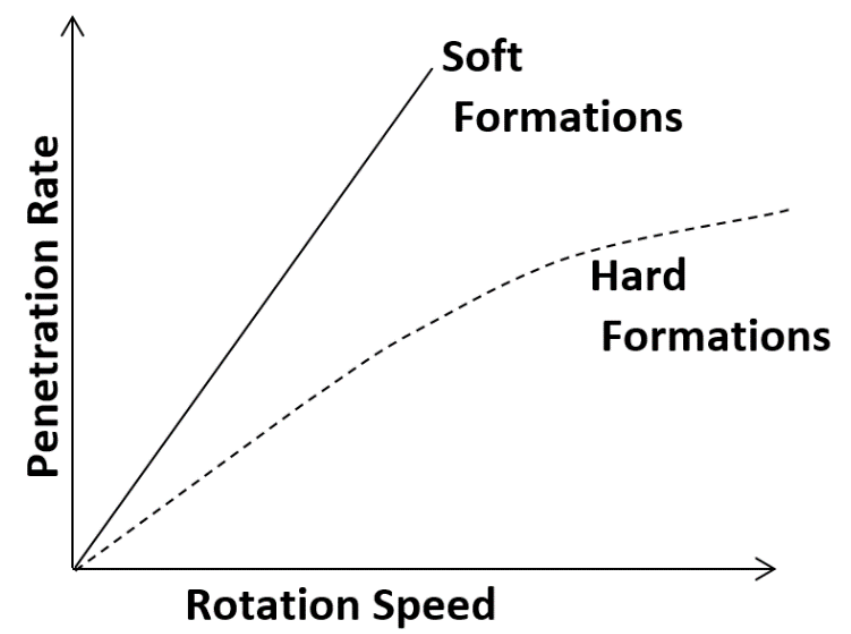

Figure 2. Relation between rotation speed and penetration rate for different formations (ADITC 2015).

Contrary to the general rule for roller bits, diamond bits give improved performance at higher rotation speeds. In hard rocks, high thrust and high rotation speed must be used together. The most critical factor in diamond bit performance is the absence of vibration. Provided that the rig and the drill string will run without vibration (or damage to the equipment), rotational speeds exceeding $1000 \mathrm{rpm}$ have resulted in improved bit performance (ADITC 2015). 


\section{Materials and Methods}

In this study, rotary blasthole drills were observed in 15 rock types with different physical and mechanic properties. The net penetration rates of the drills were calculated from the performance measurements. Rock samples were collected from the natural stone mines and the physical and mechanical properties of the rocks were determined in the laboratory. Then, the penetration rates were correlated with the rock properties. As a result, the uniaxial compressive strength, density, $\mathrm{P}$ wave velocity show strong correlations with the penetration rate. Also the effect of the rotation speed of the bit was investigated on the penetration rate.

In this study, the effect of the bit rotation speed on drillability was investigated using homogeneous rock samples which correspond to natural stones that are commercially excavated. The main reason for selecting natural stones is to utilize rocks with homogeneous properties (Table 1). The uniaxial compressive strength test, the indirect tensile strength test, the point load test, Schmidt hardness, the sonic velocity test and the density test were performed as suggested by ISRM (2007) test standards to determine the physical and mechanical properties of the samples.

Table 1. The test samples types and regions (Dursun 2012).

\begin{tabular}{|c|c|c|}
\hline Code & *Region & Type \\
\hline $\mathrm{A}_{1}$ & \multirow{5}{*}{ Nevşehir } & \multirow{5}{*}{ Tufa } \\
\hline $\mathrm{A}_{2}$ & & \\
\hline $\mathrm{A}_{3}$ & & \\
\hline $\mathrm{A}_{4}$ & & \\
\hline $\mathrm{A}_{5}$ & & \\
\hline $\mathrm{B}_{1}$ & Beyşehir & \multirow{6}{*}{ Travertine } \\
\hline $\mathrm{B}_{2}$ & \multirow{3}{*}{ Karaman } & \\
\hline $\mathrm{B}_{3}$ & & \\
\hline $\mathrm{B}_{4}$ & & \\
\hline $\mathrm{B}_{5}$ & Seydişehir & \\
\hline $\mathrm{B}_{6}$ & Ereğli & \\
\hline $\mathrm{C}_{1}$ & \multirow{2}{*}{ Konya } & \multirow{2}{*}{ Beige Marble } \\
\hline $\mathrm{C}_{2}$ & & \\
\hline $\mathrm{C}_{3}$ & Eskişehir & White Marble \\
\hline $\mathrm{D}$ & Ayrancı & Trabeige \\
\hline
\end{tabular}

*Region: All regions are in the middle part of Turkey

Drilling tests in this study were performed in the laboratory using the rotary core drilling method and a diamond drill machine. Sample length and drilling time was measured. The penetration rate was calculated with drilling time and samples length for each sample. A $42 \mathrm{~mm}$ diameter diamond bit was used and drilling tests were carried out with four different rotation speeds.

The rotation speed of the bit was selected at 451/681/998/1447 rpm, respectively, and remained constant during the drilling tests. The drilling force was set to $210 \mathrm{~N}$ and remained constant during the drilling tests. The thrust parameter was selected at $2.6 \mathrm{lt} / \mathrm{min}$. and remained constant during the drilling tests in order to ignore thrust factor on drillability. The penetration rate was determined for each sample (Table 2). A change of the penetration rate as a function of the physical-mechanical properties of rock was observed and a regression analysis was applied for investigating the relationships between penetration rate and the physical-mechanical properties of the rock. As a result exponential relations between the penetration rate and the physical-mechanical properties of rocks were developed. Results indicate that the penetration rate is strongly correlated to physical-mechanical properties of rock.

Table 2. Penetration rates for different $\mathrm{rpm}$.

\begin{tabular}{ccccc}
\hline \multirow{2}{*}{$\begin{array}{c}\text { Sample } \\
\text { Name }\end{array}$} & \multicolumn{4}{c}{ Penetration Rate (cm/min) } \\
\cline { 2 - 5 } & $\begin{array}{c}\text { At 451 } \\
\text { RPM }\end{array}$ & $\begin{array}{c}\text { At 681 } \\
\text { RPM }\end{array}$ & $\begin{array}{c}\text { At 998 } \\
\text { RPM }\end{array}$ & $\begin{array}{c}\text { At 1447 } \\
\text { RPM }\end{array}$ \\
\hline $\mathrm{A}_{1}$ & 6.66 & 9.19 & 10.43 & 17.58 \\
\hline $\mathrm{A}_{2}$ & 10.48 & 14.05 & 22.27 & 31.63 \\
\hline $\mathrm{A}_{3}$ & 9.68 & 10.90 & 19.67 & 16.33 \\
\hline $\mathrm{A}_{4}$ & 6.01 & 7.92 & 11.81 & 17.03 \\
\hline $\mathrm{A}_{5}$ & 10.41 & 13.20 & 21.01 & 27.08 \\
\hline $\mathrm{D}$ & 2.06 & 2.46 & 4.22 & 4.94 \\
\hline $\mathrm{B}_{1}$ & 2.90 & 4.67 & 9.53 & 10.14 \\
\hline $\mathrm{B}_{2}$ & 2.11 & 2.95 & 4.33 & 5.50 \\
\hline $\mathrm{B}_{3}$ & 2.15 & 3.06 & 4.45 & 4.98 \\
\hline $\mathrm{B}_{4}$ & 2.64 & 2.96 & 3.23 & 3.66 \\
\hline $\mathrm{B}_{5}$ & 2.61 & 4.38 & 7.31 & 9.54 \\
\hline $\mathrm{B}_{6}$ & 3.13 & 3.67 & 6.45 & 9.92 \\
\hline $\mathrm{C}_{1}$ & 0.89 & 1.30 & 1.83 & 2.32 \\
\hline $\mathrm{C}_{2}$ & 0.95 & 1.41 & 2.12 & 2.18 \\
\hline $\mathrm{C}_{3}$ & 1.37 & 2.02 & 2.81 & 3.39 \\
\hline
\end{tabular}

Penetration rates for four different rotation speeds were plotted against physical-mechanical properties of rocks as shown in Figures 3-Figure 8. Results of regression analysis have shown that creating models for prediction drillability could be more realistic with low rotation speeds.

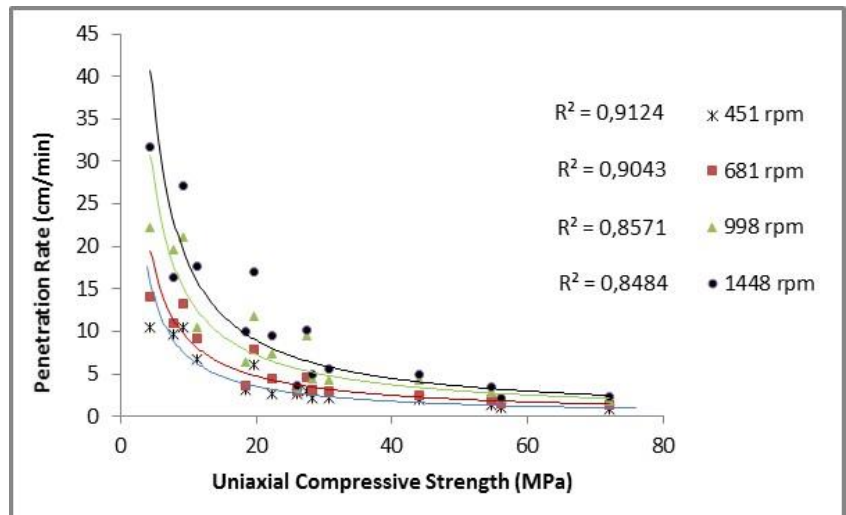

Figure 3. Relations of uniaxial compressive strength and penetration rate.

In order to investigate the effect of increasing the rotation speed on drillability, penetration rates were determined for different rotation speeds. Typical results are shown in Figure 9. 


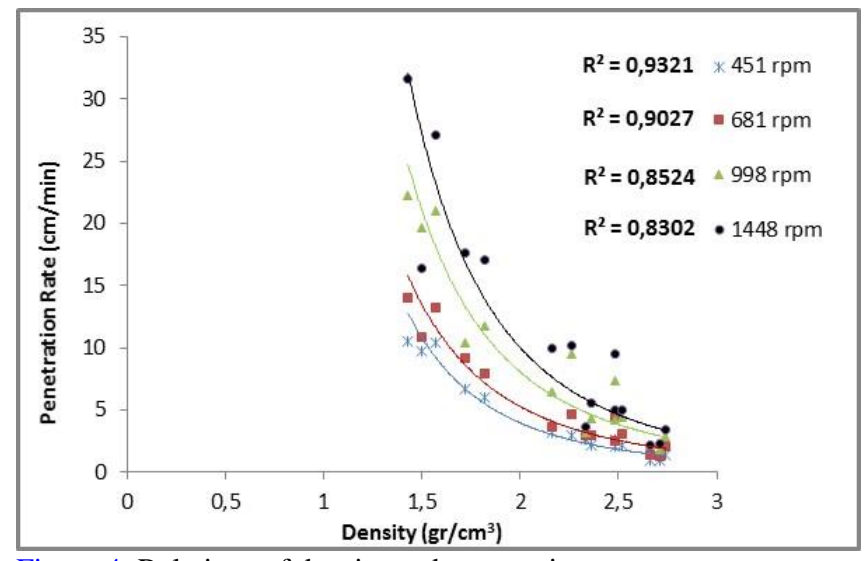

Figure 4. Relations of density and penetration rate.

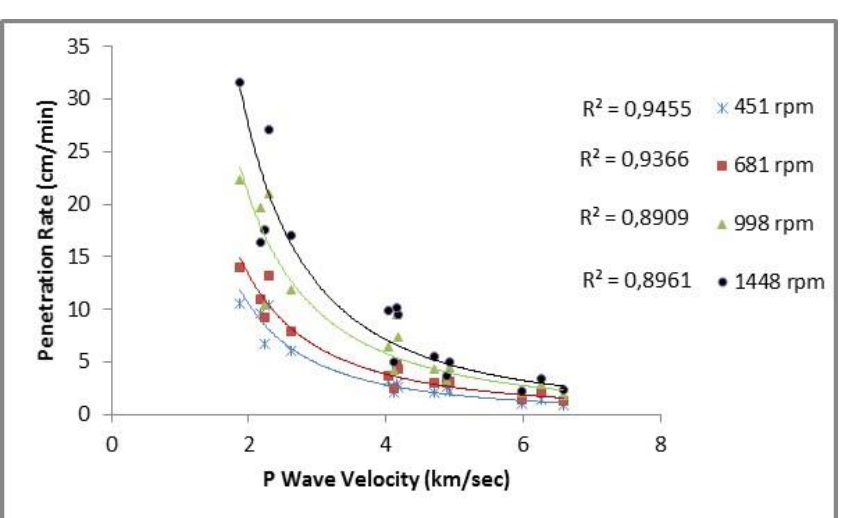

Figure 5. Relations of $\mathrm{P}$ wave velocity and penetration rate.

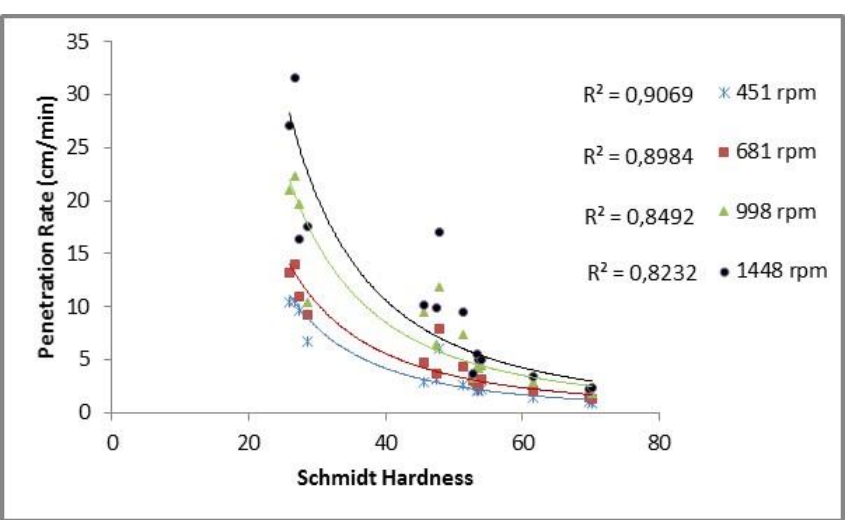

Figure 6. Relations of Schmidt hardness and penetration rate.

Different penetration rates were obtained for soft rocks and hard rocks as shown in Figure 4. It is observed that soft rocks (travertine) are significantly affected by an increasing rotation speed. An increasing rotation speed affected most Nevsehir Tufa 2, while the Konya Beige marble 2 was affected less. Nevsehir Tufa 2 is the softest formation with respect to mechanical properties and Konya Beige Marble 2 is the hardest formation in the same respect.

\section{Conclusions}

Drilling operations are vital for mining projects and tunneling both during the planning of a project and for calculating the

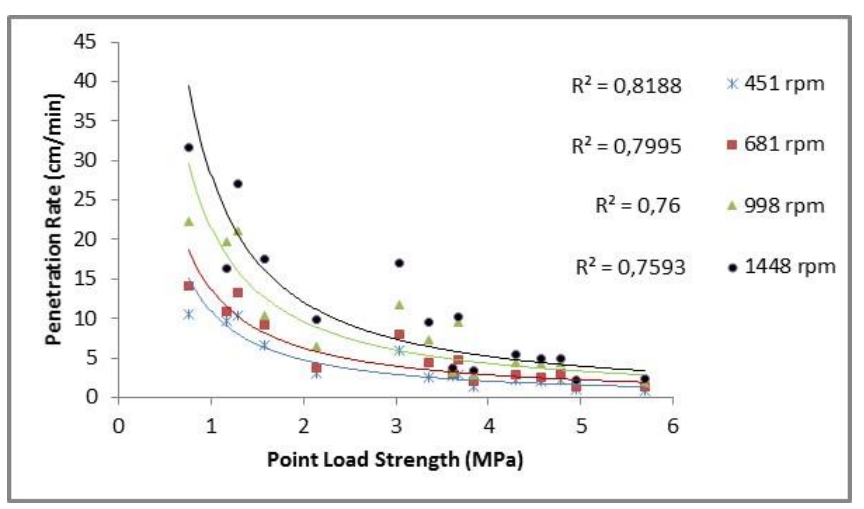

Figure 7. Relations of point load strength and penetration rate.

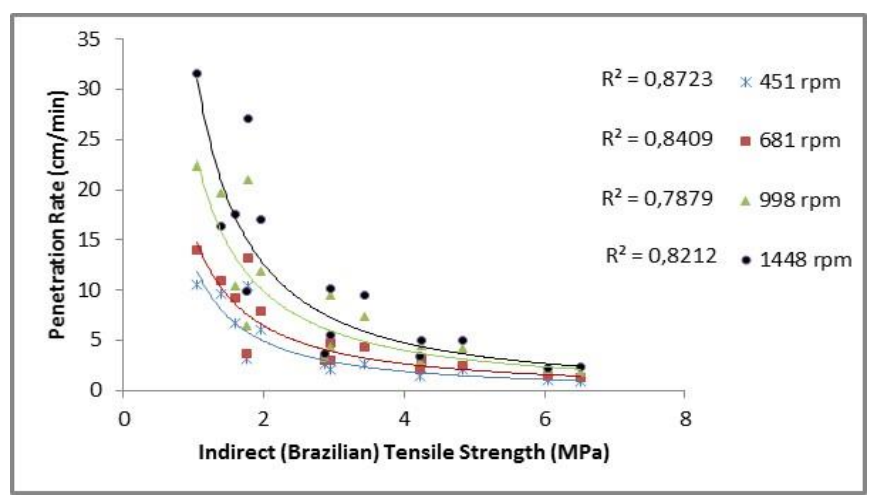

Figure 8. Relations of indirect tensile strength and penetration rate.

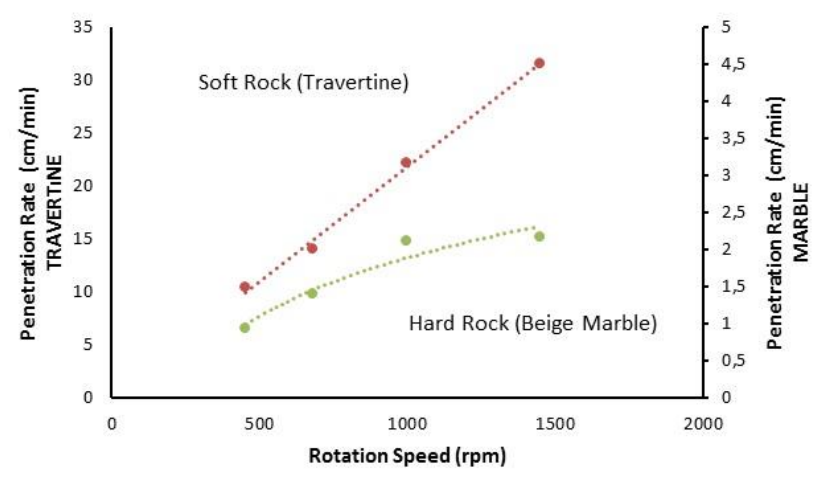

Figure 9. Typical example to show effect of rotation speed on penetration rate.

cost of a project. The selected drilling equipment and performance of the equipment can be predicted by prediction of drillability.

In this study, the efficiency of the drilling operation with different rotation speed and physico-mechanical properties of rock are investigated with respect to drillability. The selection of an appropriate rotation speed directly the performance of the drilling equipment and therefore the outcome of a drilling project. Planning a project based on physico-mechanical test results can help determine the cost of the project and the project duration. The prediction of rock drillability also allows proper selection of drilling equipment for maximum performance and cost reduction. 
If the physical and mechanical properties of rocks increase, the effect of the rotation speed on the penetration rate decreases. In other words, increasing the rotation speed of the bit slightly affects drillability on hard and solid formations. Even when considering abrasion of bit and rod, increasing the rotation speed of the bit in hard and solid formations does not provide an advantage.

\section{References}

ADITC, 2015. The drilling manual, Fifth Edition. Florida, United States, CRC Press Taylor \& Francis Group.

Bilim, N., 2011. Determination of drillability of some natural stones and their association with rock properties. Sci. Res. Essays, 6: 382 - 387.

ADITCL, 1997. Drilling: the manual of methods, applications, and management. The Australian Drilling Industry Training Committee Limited.

Dursun, A.E., 2012. Cuttability of limestone strata at northwest of Konya city. Ph.D Thesis, The Graduate School of Natural and Applied Science of Selçuk University, 284 p. (In Turkish)

Ekincioğlu, G., 2008. Evaluation of the relationships between drillability index properties and rock sawability of various limestones. M.Sc. Thesis, Süleyman Demirel University Graduate School of Applied and Natural Sciences Mining Engineering Department, Isparta 94 p. (In Turkish)

Hoseinie, S.H., Y. Pourrahimian and H. Aghababaei, 2006. Analyzing and physical modeling of joints dipping effects on penetration rate of rotary drilling in open pit mines. Proceedings, 15th International Symposium on Mine Planning and Equipment Selection, Torino, Italy, $1007-1013$.

Howarth, D.F., W.R. Adamson and J.R. Berndt, 1985. Correlation of model tunnel boring and drilling machine performances with rock properties. Int'l Rock Mech. Min. Sci., 23: 57 - 85 .

ISRM, 2007. The complete ISRM suggested methods for rock characterization, Testing and Monitoring, $\mathrm{R}$. Ulusay, J.A. Hudson (Editors).
Jimeno, C.L., E.L. Jimeno and F.J.A. Carcedo, 1995. Drilling and blasting of rocks, Rotterdam, Balkema.

Kahraman, S. 1999. Rotary and percussive drilling prediction using regression analysis. Int'l Rock Mech. Min. Sci., 36: $981-989$.

Kahraman, S., C. Balci, S. Yazici and N. Bilgin, 2000. Prediction of the penetration rate of rotary blast hole drilling using a new drillability index. Int'l Rock Mech. Min. Sci., 37: 729 - 743.

Paone, J., Madson, D and Bruce, W.E., 1969. Drillability studies - laboratory percussive drilling, Rock Drilling, U.S. Dept. of the Interior, Bureau of Mines, p. 22.

Pathinkar, A.G., G.B. Misra, 1976. A critical appraisal of the Protodyakonov index, Int'1 Rock Mech. Min. Sci., 13: $249-251$.

Perrin, V.P., M.G. Wilmot and W.L. Alexander, 1977. Drilling index-a new approach to bit performance evaluation. SPE/IADC drilling conference, Amsterdam, The Netherlands, 199 - 205.

Protodyakonov, M.M., 1963. Mechanical properties and drillability of rocks. Proceedings, 5th Rock Mechanics Symposium, Minnesota, USA, 103 - 118.

Rabia, H., 1985. Oilwell drilling engineering: principles and practise, Graham and Tromtman, Huddersfield, England, p. 322.

Soyer E., 2009. Investigations on the effect of strength and petrographic properties of rocks on their drillability. M.Sc. Thesis, Graduate School of Natural and Applied Sciences Department of Mining Engineering, Zonguldak, 200 p. (In Turkish)

Taheri A., Q. Qao and E. Chanda, 2016. Drilling penetration rate estimation using Rock Drillability Characterization index. Journal of the Institution of Engineers (India), series D, $1-12$.

Tandanand, S. and H.F. Unger, 1975, Drillability determination - A drillability index of percussive drills. US Bureau of Mines, RI 8073.

Thuro, K., 1997. Drillability prediction - geological influences in hard rack drill and blast tunneling. Geol. Rundsch, 86: 426 - 438. 